\title{
Predictors of work satisfaction among SHOs during accident and emergency medicine training
}

\author{
J. HEYWORTH* T. W. WHITLEY ${ }^{\dagger}$, E. J. ALLISON JR ${ }^{+} \&$ \\ D. A. REVICKI ${ }^{+}$ \\ *Department of Accident and Emergency Medicine, Queen Alexandra Hospital, \\ Portsmouth P06 $3 \mathrm{LY}$ and ${ }^{\dagger}$ East Carolina University School of Medicine, U.S.A.
}

\section{SUMMARY}

The purpose of this study was to assess the ability of work-related stress, and other work environment characteristics that might affect stress, to predict work satisfaction among senior house officers (SHOs) during accident and emergency (A\&E) training. Questionnaires were returned by 365 SHOs, who indicated their year in training, the number of hours worked per week, the type of training hospital, the number of new A\&E attendances per year, the ratios of patients and consultants to SHOs at their training hospitals and their likelihood of specializing in A\&E. They also completed inventories measuring work-related stress, task and role clarity, work group functioning and work satisfaction. Scores on the satisfaction scale served as the dependent variable in a multiple regression equation. Using an alpha level of 0.05 , a significant relationship was detected between satisfaction and the 10 independent variables $(P=0.0001)$. Direct relationships between task and role clarity $(P=0.0001)$ and work group functioning $(P=0.0002)$ were significant, as were inverse relationships between stress $(P=0.0001)$ and the number of new attendances $(P=0.0321)$. Management practices, such as orientation sessions, that define tasks and roles, enhance work group cohesiveness and mitigate against stress, should result in increased satisfaction among SHOs.

Address for Correspondence: John Heyworth, MB, FRCS Consultant in Accident and Emergency Queen Alexandra Hospital Portsmouth P06 3LY England.

Presented at the EMRS/SAEM - First International Emergency Research Conference, Edinburgh, Scotland, October, 1990. 
The work-related stresses and strains experienced during postgraduate medical training has stimulated much research and commentary in recent years, particularly in the United States (Butterfield, 1988). The response (Barry, 1987; Burns-Cox et al., 1987; Dowling, 1987; East, 1987) to Firth-Cozens' (1987) initial report of her survey of junior doctors in Great Britain reflects increasing interest in the topic in this country. Both agreement (Dowling, 1987) and disagreement (Barry, 1987) with Firth-Cozens' contention that coping with stress in the clinical setting should be included in undergraduate medical education were expressed, as was disagreement that the first year after medical school was the most stressful (East, 1987). Changes in the work environment (Barry, 1987), particularly hours of work, were suggested, and programmes to help physicians cope with postgraduate training were described (Burns-Cox et al., 1987; Dowling, 1987). Despite concerns about the negative psychological effects of residency training in the United States, the view also has been expressed that while work-related stress is freqently considered undesirable, it is necessary for the acquisition of knowledge and skills and the development of desirable attitudes and behaviours (Resident Services Committee, 1988). Thus, the problem may not necessarily be one of eliminating stress, but rather one of minimizing exposure to sources of stress that do not contribute to the professional growth and development of physicians undergoing postgraduate training. Nonphysician tasks have been mentioned in this regard (Levinsky, 1988), as have the stresses these physicians encounter in their personal lives (Levin, 1988; Resideng Services Committee, 1988), the effects of which may be compounded by the stresse of training e.g. long hours (McCall, 1988).

The studies by Firth-Cozens $(1987 ; 1989)$ suggest that the sources and effects of work-related stress are similar in physicians undergoing postgraduate training in the United Kingdom and the United States.

However, the relationship between the work-related stress experienced by these physicians and the satisfaction they derive from their work has not been studied extensively, particularly in settings involving the provision of emergency medical care. Therefore, the purpose of this study was to assess the ability of work-related stress, in combination with other characteristics of the work environment that might affect stress, to predict work satisfaction among SHOs during A\&E training.

\section{MATERIALS AND METHODS}

A cross-sectional survey of SHOs in the middle part of their six-month training posts in A\&E medicine was conducted in 1989. The questionnaires constructed for the survey were mailed so that SHOs would receive them during the third month of their training posts. Of 675 questionnaires mailed, 365 were returned for a response rate of $54.1 \%$.

SHOs were asked to indicate their year in postgraduate medical training, the number of hours they worked per week, and the likelihood that they would select A\&E medicine as a career specialty. In addition, SHOs were asked whether they were training in teaching or district general hospitals, how many new attendances 
were seen in the $A \& E$ department each year, and how many senior staff worked in the A\&E department. The questionnaire also contained scales to assess the SHOs' perceptions of work-related stresses and strains, the clarity of the definitions of their tasks and roles, the cohesiveness of their work groups and their overall satisfaction with work.

Work-related strain - the individual physiological, psychological and behavioural reactions of the SHOs to stresses in their work environment - was assessed with the Work-Related Strain Inventory (WRSI). Respondents to the WRSI are asked to evaluate their personal productivity, relationships with co-workers and ability to forget or ignore work-related matters when off-duty. The WRSI has been shown to be reliable and valid in studies of a variety of health care providers (Revicki et al., 1991). The internal consistency reliability coefficient (Cronbach's alpha) for the SHOs who participated in this survey was 0.86 .

The SHOs' perceptions of task and role clarity, work group cohesiveness, and satisfaction with work were assessed with Likert scales adapted from an instrument developed by Gray-Toft \& Anderson (1985). Statements on the three scales were scored so that high scores were obtained by SHOs who reported that they knew what was expected of them at work, who viewed their work groups as cohesive, supportive units, and who were satisfied with aspects of their work such as rotas, recognition, and educational opportunities. Cronbach's alpha for the 12-statement task and role clarity scale was 0.73 ; for the 10-statement work group functioning scale was 0.82 ; and for the 12-statement work satisfaction scale was 0.80 .

A multiple regression model was tested using 10 independent variables to predict the SHOs' satisfaction with work, as evidenced by their scores on the work satisfaction scale. In addition to the type of training hospital, three other dichotomous independent variables were included in the model. These three variables were created by classifying SHOs according to whether they were in their first year of postgraduate training or later years, whether they reported working more or less than $50 \mathrm{~h}_{\text {week }}{ }^{-1}$, and whether they indicated that they were likely or unlikely (including reponses reflecting uncertainty) to select $A \& E$ as a specialty. The number of new A\&E attendances per year served as an independent variable, as did the ratio of new attendances to the number of SHOs in A\&E training and the ratio of senior A\&E staff to the number of SHOs in A\&E training. The remaining independent variables were scores on the scales assessing workrelated stress, task and role clarity, and work group functioning. An alpha level of 0.05 served as the criterion for determining the statistical significance of both the regression model and the individual independent variables.

\section{RESULTS}

The number and percentage of SHOs in each category of the four dichotomous independent variables are shown in Table 1 . Nearly $60 \%$ of the SHOs were in their first year of post-registration training. Two-thirds reported working more than $50 \mathrm{~h}_{\text {week }}^{-1}$, and a similar proportion was training in district general hospitals. Only $7.7 \%$ indicated that they were likely to specialize in A\&E medicine.

Descriptive statistics for the six continuous independent variables and the 
Table 1. Frequency distributions for the categorical independent variables

\begin{tabular}{lrc}
\hline & $n$ & \% of respondents \\
\hline Stage of training & & \\
$\quad$ Year 1 & 213 & 59.2 \\
$\quad$ Years 2-4 & 147 & 40.8 \\
$\quad$ No response & 5 & \\
Hours week & & \\
$\quad<50 \mathrm{~h}$ & 114 & 32.7 \\
$\quad 50 \mathrm{~h}$ & 235 & 67.3 \\
$\quad$ No response & 16 & \\
Training hospital type & & \\
$\quad$ Teaching & 117 & 67.5 \\
$\quad$ District General & 243 & \\
$\quad$ No response & 5 & 92.3 \\
Likelihood of A\&E specialization & & 7.7 \\
$\quad$ Unlikely & 337 & \\
Likely & 28 & \\
\hline
\end{tabular}

Table 2. Descriptive statistics for the continuous independent variables and the dependent variable

\begin{tabular}{lcccc}
\hline & Mean & Median & $\begin{array}{c}\text { Potential } \\
\text { score } \\
\text { range }\end{array}$ & $\begin{array}{c}\text { Standare } \\
\text { deviation }\end{array}$ \\
\hline $\begin{array}{l}\text { Independent variables } \\
\text { A\&E patients per y'ear }\end{array}$ & 56432 & 50000 & 11730 & 21450 \\
A\&E patients per SHO & 7975 & 7600 & 140000 & 2471 \\
Senior staff per SHO & & & $977-$ & 0.38 \\
Work-related stress & 0.46 & 0.40 & 17000 & 9.8 \\
Task and role clarity & 35.1 & 34 & $(18-72)$ & 6.6 \\
Work group functioning & 40.5 & 41 & $(16-60)$ & \\
Dependent variable & 33.0 & 34 & $(10-48)$ & 7.4 \\
Work satisfaction & 37.9 & 38 & $(12-60)$ & \\
\hline
\end{tabular}

dependent variable are shown in Table 2. The A\&E departments in which the SHOs were training saw an average of just over 56000 new attendances each year, which yielded a ratio of approximately 8000 patients per SHO per year. Less than half as many senior staff as SHOs were employed in the hospitals in which the latter were training. Since WRSI scores can range from 18 to 72 , the mean score of 35.1 indicates that the respondents were not experiencing extremely high levels of work-related stress. On the other hand, the relationships of the mean scores to the maximum possible scores on the other affective scales indicate that the SHOs considered their tasks and roles to be reasonably clear, perceived their work groups to be cohesive, smoothly functioning units, and generally were satisfied with the aspects of the work environment assessed in this survey. 
The relationship between the 10 independent variables and the dependent variable was statistically significant $\left(\mathrm{F}_{10229}=18.93, P<0.0001\right)$. The model accounted for $45 \%$ of the variance in scores on the work satisfaction scale. Statistically significant independent variables (Table 3) included scores on the WRSI, task and role clarity work group functioning scales and the number of new A\&E attendances per year. The standard regression coefficients (Table 3) reveal that the clarity with which the SHO's tasks and roles were defined was the most powerful predictor of satisfaction with work. Work-related stress and work group cohesiveness were equally powerful predictors, and the number of new attendances per year was the least powerful, although statistically significant, predictor.

The relationships between the significant independent variables and the dependent variable were as expected. On the one hand, SHOs who viewed their tasks and roles as clearly defined and who perceived their work groups as cohesive, smoothly functioning units reported higher levels of satisfaction with work. On the other hand, SHOs who perceived higher levels of work-related stress or were training in hospitals with higher numbers of new attendances each year reported lower levels of satisfaction. No statistically significant interaction effects between or among variables were detected.

A pilot of the residual work satisfaction scores on the original work satisfaction scores confirmed the basic appropriateness of the linear model. The model was somewhat ill-conditioned, but neither collinearity diagnostics nor bivariate correlation coefficients suggested potential causes. Seven implausible responses to the question regarding the number of new attendances per year were deleted, but removal of these outliers had virtually no effect on the model.

\section{DISCUSSION}

Previous studies by Firth-Cozens $(1987,1989)$ and those in the United States cited by Butterfield (1988) typically have focused on the negative effects of stress, or distress, on the lives of physicians pursuing postgraduate medical training.

Table 3. Regression results

\begin{tabular}{lcrc}
\hline & $\begin{array}{c}\text { Standardized } \\
\text { regression } \\
\text { Independent Variable }\end{array}$ & $t$ & $P$ \\
\hline Training hospital type & 0.03 & -0.57 & 0.5688 \\
Stage of training & -0.10 & -1.92 & 0.0561 \\
Hours worked per week & -0.10 & -1.86 & 0.0648 \\
Likelihood of A\&E & 0.03 & 0.60 & 0.5516 \\
A\&E patients per year & -0.13 & -2.16 & 0.0321 \\
A\&E patients per SHO & 0.00 & 0.01 & 0.9940 \\
Senior staff per SHO & 0.01 & 0.22 & 0.8289 \\
Work-related stress & -0.23 & -4.11 & 0.0001 \\
Task and role clarity & 0.36 & 5.74 & 0.0001 \\
Work group functioning & 0.23 & 3.76 & 0.0002 \\
\hline
\end{tabular}


However, distress has been distinguished from eustress, or good stress, and the direct relationship between the latter and productivity has been noted (Matheson, 1990). In fact, the absence of stress has been equated to a state of zero entropy (Koltonow, 1989). Thus, it is not surprising that the results of this study provide support for Firth-Cozens' (1987) finding that junior doctors basically enjoy their work.

The results of this study do indicate that although stress did have the expected negative impact on satisfaction with work, the clarity with which the SHOs' tasks and roles were defined was the most powerful predictor of satisfaction. Given that the most distressed junior doctors surveyed by Firth-Cozens (1987) reported a lack of knowledge about what was expected of them and feeling overwhelmed by responsibility, this result is also unsurprising. One potential explanation for this finding is offered by Dudley (1990), who expressed the opinion that junior doctors do not receive as much support from senior staff as they did in the past. This lack of support has resulted in the expectation that juniors will take action without conferring with seniors, a state of affairs Dudley (1990) attributes to inadequately defined rules. In a response to Dudley's editorial, Davison (1990) states that junior doctors do not seek guidance and support from senior staff because such requests will be viewed as an admission of dissatisfaction with some aspect of work and may result in a poor reference. Thus, anxiety about references may deter junior doctors from seeking to clarify their roles and responsibilities, and may lead to diminished satisfaction with work.

Dudley (1990) also attributes some of the distress experienced by junior doctors to lack of leadership, which could be demonstrated by reporting to work on time responding immediately to requests and by displaying the personal commitment expected of others. Similar concerns about the need for adequate role models for residents in the United States have been expressed by Asch \& Parker (1988), who also supported the striking of a balance between resident education and patient care. This view, in conjunction with Dudley's concerns about lack of support and leadership, suggests that senior staff should be mindful that junior doctors are in training and may need assistance in defining their roles and responsibilities and in successfully discharging some of their patient care tasks. The results of this study indicate that the provision of such assistance will enhance junior doctors' satisfaction with their work.

The negative effects of competition described by Davison (1990), which included suspicion and low morale, suggest one explanation for the significant positive relationship between work group cohesiveness and satisfaction with work. Junior doctors who work in environments characterized by friendly, supportive relationships with their peers may reasonably be expected to be more satisfied. Within the larger work group, however, relationships with senior staff have been identified as sources of difficulty for juniors (Firth-Cozens, 1987, 1989; Dudley, 1990), and relationships with nurses and administrators have been identified as sources of stress for emergency medicine residents in the United States (Zun et al., 1988). Potential problems with administrators and other health care professionals have prompted recommendations in the United States that residency program directors monitor resident interactions with these groups to ensure that they are governed by clear expectations and mutual respect (Resident Services Committee, 1988). 
As post-registration training in the United Kingdom is characterized by frequent job changes (Matheson, 1990), the results of this study suggest that senior staff who actively attempt to integrate juniors into both the A\&E department and larger hospital work groups will be rewarded by training junior doctors who are more satisfied with their work and more motivated to learn.

Based on the larger number of studies reviewed by Butterfield (1988) and the findings of Firth-Cozens $(1987,1989)$ which describe the negative effects of stress, the significant inverse relationship between stress and satisfaction was anticipated. Despite the large number of studies of stress during postgraduate training, few have dealt specifically with emergency medicine trainees. Zun et al. (1988) have identified sources of stress for residents including shift changes, irregular schedules, and pressure to treat patients as expediently as possible, as well as the relationships with the medical staff and other health care professionals noted earlier. The results of a national survey of residents in the United States revealed that women residents reported higher levels of stress than men and that both women and unmarried residents reported more symptoms of depression (Whitley et al., 1989). Similar results were obtained when physicians pursuing postgraduate training in emergency medicine in the United States, the United Kingdom and Australasia were compared (Whitley et al., 1991). The results of these studies, in combination with those conducted by Firth-Cozens $(1987,1989,1990)$, suggest that sources of stress for physicians in postgraduate training who provide emergency health care are similar in the United Kingdom and in the United States.

Overwork was cited as a source of stress by the junior doctors surveyed by Firth-Cozens (1987), which may explain the significant inverse relationship between the number of new attendances seen in the A\&E department each year and satisfaction with work. Firth-Cozens (1989) also observed that complaints about overwork may be a defensive reaction against confronting other aspects of work that cause anxiety. The more powerful role in predicting satisfaction played by other aspects of the work environment, coupled with the failure of hours worked per week to surface as a significant predictor, suggests that her observation may also apply to this study. The supposition that junior doctors who have clearly defined tasks and roles and who work in supportive, efficient groups will be able to cope with greater numbers of patients and longer hours while still enjoying their work certainly appears reasonable.

Although Firth-Cozens $(1987,1989,1990)$ did not differentiate the junior doctors she surveyed by probable specialty choice or by training post, generalization of her findings to junior doctors working in $A \& E$ departments seems reasonable, as does the supposition that training in A\&E medicine is no less stressful in the United Kingdom than in the United States or other locations. Moreover, the emergence of A\&E medicine as a specialty in the United Kingdom has allowed some of the problems that may have caused stress to be addressed. For example, increasing numbers of consultants have raised levels of teaching and support for junior $A \& E$ staff, which may explain the fact that neither the ratio of new A\&E attendances nor of senior staff to the number of SHOs were significant predictors of satisfaction with work. Nevertheless, in departments with a high volume of patient attendance, the majority of patient encounters inevitably are with the SHO in isolation and senior staff advice, overall, is rarely sought despite the presence of senior A\&E 
staff and repeated reinforcement of their desire to be consulted if in doubt or difficulty.

Firth-Cozens (1987) also provided evidence of higher levels of negative affective responses among junior doctors working in teaching hospitals. However, the type of hospital in which the SHOs in this survey were working was not a significant predictor of satisfaction with work. Similarly, the likelihood of specializing in A\&E medicine was not a significant predictor of satisfaction. Of those surveyed, only $7.7 \%$ considered it likely that they would pursue A\&E medicine as a career, a persistent idiosyncracy of training in the United Kingdom, where the concept of general professional training requires periods in specialties for which there may be little interest or motivation. As studies in the United States have shown that rotations in emergency departments are viewed as stressful (Schwartz et al., 1987) or associated with depression (Reuben, 1985), junior doctors for whom 6 months training in $\mathrm{A} \& \mathrm{E}$ are viewed as a hurdle to overcome to complete general professional training for general practice or surgery, might be particularly vulnerable to any stressful or unsatisfactory aspects of working in the A\&E department. Thus, the absence of intention to specialize in A\&E medicine might have had a negative impact on satisfaction with work, but this was not the case in this study.

The final nonsignificant predictor of satisfaction with work was level of training. This finding may be due simply to the fact that the characteristics of the work environment described in the preceding paragraphs were the most important determinants of satisfaction with work, regardless of the SHO's level of training Additionally, evidence has presented that residents in the United States experience stress at all levels of training (Schwartz et al., 1987; Whitley et al., 1989). Similarly satisfaction with work may not vary significantly over the course of training.

Before considering the implications of this study, some potential limitations should be addressed. Firstly, the survey was cross-sectional, so that the data reflect the SHOs' attitudes at a limited point in time. However, the mailing schedule for ths survey was adopted to provide an opportunity for SHOs to adjust to the A\&E work environment while avoiding the lower response rate that might result from a mailing late in the training period when SHOs were busy completing their training and preparing to move to their next posts.

A second potential limitation is bias due to sampling error. Although the $54 \%$ response is comparable to the one estimated for a similar survey of emergency medicine residents in the United States (Whitley et al., 1989), the possibility exists that SHOs who responded differed from those who did not on important, but unidentifiable, variables. Moreover, because the data were obtained via self-report, SHOs who responded may have underestimated or overestimated their satisfaction with work or their standing on the other affective scales. Finally, only SHOs who generally were satisfied with their jobs may have responded, or vice versa.

Despite these potential limitations, the results of this study have implications for post-registration training in the United Kingdom, particularly as the impending changes in the National Health Service noted by Matheson (1990) increase emphasis on costs and profits. Matheson also notes that junior doctors are concerned about the quality of their training and the conditions in which they work, and he states that the medical profession should be more supportive of the youngest and most vulnerable members of the profession. The recommendations for providing such support that follow are suggested by the results of this study. 
The impact of clearly defined tasks and roles on satisfaction with work suggests that orientation sessions such as those recommended by the Resident Services Committee (1988) that address the roles junior doctors are expected to play, the responsibilities they are expected to assume and the tasks they are expected to perform will be beneficial. Explanation of such expectations also should enhance the functioning of work groups as junior doctors will know not only what is expected of them, but also what is expected of their peers. If these sessions are expanded to include discussions of the roles and responsibilities of administrators and other health care professionals, or preferably meetings with representatives of the groups, conflicts between junior doctors and members of these groups may be minimized.

The importance of clearly defined tasks and roles also suggests that senior staff should play an active role in educating junior doctors, particularly with respect to helping juniors set realistic goals and providing both positive and negative evaluation of their progress. Such monitoring also would provide opportunities to offer support to juniors who are experiencing distress from both work-related and personal sources. In addition to job performance, expansion of the monitoring process to include attention to aspects of the work environment such as rota, the number of hours worked, and improvement of facilities, i.e., canteen facilities, sleeping arrangements and areas for socializing, should also improve morale and work group cohesiveness.

Senior staff also should become familiar with some of the sources of distress identified in reports by Firth-Cozens $(1987,1989)$ and the Resident Services Com mittee (1988) to be alert to signs of maladaptation and prepared to provide support to junior doctors who are experiencing unacceptably high levels of distress. Formal and informal discussions of ethical questions or about issues of death and suffering amongst patients might be useful in this regard. Junior doctors also should be able to voice their vulnerability and discuss their mistakes without perceived threat to their careers. In addition to individual counselling, support groups, which have been used successfully by others (Brashear, 1987), should enable junior doctors to know each other on a more personal level and thus facilitate the provision of mutual support.

\section{ACKNOWLEDGEMENT}

The authors are grateful to Mrs J. Farmer for her capable assistance with data storage and manuscript preparation.

\section{REFERENCES}

Asch D. A. \& Parker R. M. (1988) The Libby Zion case: One step forward or two steps backward. New England Journal of Medicine 318, 771-775.

Barry P. W. (1987) Emotional distress in junior house officers (letter). British Medical Journal $295,780$.

Brashear D. B. (1987) Support groups and other supportive efforts in residency programs. Journal of 
Medical Education 62, 418-424.

Burns-Cox C. J., Kearsey K. \& Roberts J. B. M. (1987) Emotional distress in junior doctors (letter). British Medical Journal 295,-926.

Butterfield P. S. (1988) The stress of residency: A review of the literature. Archives of Internal Medicine 148, 1428-1435.

Davison P. S. (1990) Stress in junior doctors (letter). British Medical Journal 301, 342.

Dowling S. (1987) Emotional distress in junior doctors (letter). British Medical Journal 295, 926.

Dudley H. A. F. (1990) Stress in junior doctors. 1. Stress and support (editorial). British Medical Journal $301,342$.

East M. C. (1987) Emotional distress in junior house officers (letter). British Medical Journal $295,370$.

Firth-Cozens J. (1987) Emotional distress in junior house officers. British Medical Journal 295, 533-536.

Firth-Cozens J. (1989) Stress in medical undergraduate and house officers. British Journal of Hospital Medicine 41, 161-164.

Firth-Cozens J. (1990) Sources of stress in women junior house officers. British Medical Journal 301, $89-91$.

Gray-Toft P. \& Anderson J. G. (1985) Organizational stress in the hospital: Development of a model for diagnosis and prediction. Health Services Research 19, 753-774.

Koltonow S. H. (1989) Who's stressing whom? (editorial) Annals of Emergency Medicine 18, $103-104$.

Levin R. (1988) Beyond "The Men of Steel": The origins and significance of house staff training stress. General Hospital Psychiatry 10, 114-121.

Levinsky N. G. (1988) Compounding the error. Neze England Journal of Medicine 318, 778-780

Matheson K. H. (1990) Stress and stress counselling. Postgraduate Medical Journal 66, 738-742.

McCall F. B. (1988) The impact of long working hours on resident physicians. New England Journal of Medicine 318, 775-778.

Resident Services Committee, Association of Program Directors in Internal Medicine. (1988) Stress and impairment during residency training: Strategies for reduction, identification, and management. $\underbrace{}_{<}$ Annals of Internal Medicine 109, 154-161.

Reuben D. B. (1985) Depressive symptoms in medical house officers: Effects of level of training and work rotation. Archives of Internal Medicine 145, 286-288.

Revicki D. A., May H. J. \& Whitley T. W. (1991) Reliability and validity of the Work-Related Strain $\stackrel{0}{\supset}$ Inventory among health professionals. Behavioral Medicine 17, 111-120.

Schwartz A. J., Black E. R., Goldstein M. G., Jozefowicz R. F. \& Emmings F. G. (1987) Levels and causes of stress among residents. Journal of Medical Eduction 62, 744-753.

Whitley T. W., Gallery M. E., Allison E. J. Jr. \& Revicki D. A. (1989) Factors associated with stress among emergency medicine residents. Annals of Entergency Medicine 18, 1157-1161.

Whitley T. W., Allison E. J. Jr., Gallery M. E., Heyworth J., Cockington R. A., Gaudry R. \& Revicki D. A. (1991) Work-related stress and depression among physicians pursuing postgraduate medical training in emergency medicine: An international study. Annals of Emergency Medicine 20, 992-996.

Zun L., Kobernick M. \& Howes D. S. (1988) Emergency physician stress and morbidity. American Journal of Energency Medicine 6, 370-374. 